\title{
EXPERIMENT AS AN INTEGRAL PART OF THE METHODOLOGY OF COMPARATIVE RESEARCH
}

\author{
Vera A. Pishchalnikova \\ Moscow State Linguistic University, Moscow, Russia
}

\begin{abstract}
The author offers an associative experiment as an effective means for identifying the psychologically relevant content of the word and its specificity in various languages. The comparative study of lexical units is usually based on explanatory dictionaries, which cannot fix the dynamics of language units connected to the oral activity of individuals. The author theoretically justifies the identification of a set of features of association, which make it possible to effectively compare the structure and content of associative fields of different words and languages. It is highlighted in the article that it is important to interpret the relation between stimulus and reaction, rather than the content of a particular associate. It allows us to offer fundamentally different parameters for creating associative fields of compared languages. The field is based now only on frequency of associates. The "stimulus - reaction" relation that is regarded as a verbal action makes it possible to actualize the motive of the verbal action in the semantics of associates. This allows us to clarify methods of identifying the personal meaning represented by the associate and to find out dominant features of the association that may become the basis for determining the semantic difference between meanings. The author sets parameters by which one can estimate how the meaning of a word of the compared languages changes. The parameters help to define: a decrease in the number of actualized semantic signs in different zones of the associative field; reduction of the diversity of reactions and the number of single reactions in the associative fields; the prevalence of the number of conceptual and operational reactions over emotionally evaluative reactions and reactionsconceptions; a decrease in the number of metaphorical and nationally specific or culturally significant reactions; changing of the positive connotation of a lexeme to neutral and negative; the number of rejections (in percentage correlation with the total set of associates).
\end{abstract}

Key words: methodology, experiment, speech action, associate, stimulus, associative field, meaning, semantics.

Citation. Pishchalnikova V.A. Experiment as an Integral Part of the Methodology of Comparative Research. Vestnik Volgogradskogo gosudarstvennogo universiteta. Seriya 2. Yazykoznanie [Science Journal of Volgograd State University. Linguistics], 2019, vol. 18, no. 3, pp. 52-63. (in Russian). DOI: https://doi.org/10.15688/ jvolsu2.2019.3.4

УДК 81’0:001.891.5

Дата поступления статьи: 29.03.2019

ББК 81.006 Дата принятия статьи: 02.09.2019

\section{ЭКСПЕРИМЕНТ КАК СОСТАВНАЯ ЧАСТЬ МЕТОДОЛОГИИ СОПОСТАВИТЕЛЬНЫХ ИССЛЕДОВАНИЙ}

\author{
Вера Анатольевна Пищальникова
}

\author{
Московский государственный лингвистический университет, г. Москва, Россия
}

Аннотация. В статье показана эффективность использования эксперимента для выявления психологически актуального содержания слова и его специфики в различных языках в противоположность традиционным сопоставительным исследованиям лексических единиц, опирающимся на толковые словари, которые не могут зафиксировать динамику языковых единиц, связанную с речевой деятельностью индивидов. Теоретически обосновано установление совокупности признаков ассоциирования, позволяющих эффективно сопоставлять структуру и содержание ассоциативных полей разных слов и языков. Аргументирована важность интерпретации отношения «стимул - реакция», а не конкретного содержания ассоциата, что дает возможность предложить принципиально иные параметры моделирования ас- 
социативного поля в сравниваемых языках, строящегося в современной лингвистике только на частотности ассоциатов. Отмечено, что это соотношение, рассматриваемое как речевое действие, позволяет актуализировать в семантике ассоциатов мотив речевого действия, уточнить приемы обнаружения личностного смысла, представленного ассоциатом, и выявить доминантные признаки ассоциирования, которые могут стать основанием для определения семантической разницы сопоставляемых значений. Выделены параметры, позволяющие установить изменение значения слова в сравниваемых языках: уменьшение количества актуализируемых смысловых признаков в разных зонах ассоциативного поля; снижение степени разнообразия реакций и количества единичных реакций в составе ассоциативных полей; преобладание количества понятийных и операциональных реакций над эмоционально-оценочными и реакциями-представлениями; уменьшение количества метафорических национально специфичных или культурно значимых реакций; смена положительной коннотации лексемы на нейтральную и отрицательную; число отказов от ассоциирования (в процентном соотношении со всей совокупностью ассоциатов).

Ключевые слова: методология, эксперимент, речевое действие, ассоциат, стимул, ассоциативное поле, смысл, семантика.

Цитирование. Пищальникова В. А. Эксперимент как составная часть методологии сопоставительных исследований // Вестник Волгоградского государственного университета. Серия 2, Языкознание. - 2019. T. 18, № 3. - C. 52-63. - DOI: https://doi.org/10.15688/jvolsu2.2019.3.4

\section{Введение}

Культурная асимметрия определяется совокупностью взаимосвязанных культурноисторических факторов: системой ценностей общества, спецификой его социокультурной организации, религиозными взглядами и личностными потребностями носителей лингвокультуры, намерениями и целями индивидов, что в целом специфически отражается в структуре и содержании ассоциативно-вербальной сети. Поэтому психолингвистическое исследование вербальных ассоциаций, способных верифицировать философские и социологические построения, в современной науке приобретает все большую актуальность. Особое место занимает экспериментальное изучение базовых ценностей общества, выполняющих для индивида и социума ориентирующую, нормативную и интерпретативную функции: человек воспринимает базовые ценности как свои личные предпочтения, определяющие его отношение к действительности, самому себе и в целом смысл человеческого бытия. Философы и социологи рубежа XIX-XX вв. теоретически рассматривали зависимость системы ценностей от специфики культуры, функции ценностей и их роль в жизни индивида и социума, соотношение факта и ценности, касались проблемы динамичности ценностей и условий их кризиса и смены и т. д. При этом сущностные свойства ценности как научного концеп- та представлялись по-разному: от отождествления с новой идеей до понимания ценности как культурно-исторического стереотипа, в том числе поведенческого, детерминирующего повседневное функционирование человека и общества, в частности, мотивы индивидуальных или коллективных действий. Вне определенной исторически сложившейся системы ценностей общество существовать не может, хотя в каждой системе имеется специфическое соотношение универсальных и национально обусловленных ценностей, разное их количество и степень проявления, неодинаковый характер взаимодействия с другими, иные ценностные доминанты. Складываются системы ценностей только в результате аксиологической деятельности человека, представляющей собой обязательный, скрытый или эксплицированный момент его бытия, так или иначе фиксированный в ассоциативно-вербальной сети.

С расширением межкультурных контактов в современном мире асимметрия ценностных систем все более препятствует эффективной коммуникации, и потому необходимо детальное изучение культурных ценностей, казалось бы, вполне соотносимых по содержанию, но на деле оказывающихся включенными в разные структуры и регулирующие разные социальные и культурные процессы.

Все сказанное требует выявления психологически актуальных смыслов, соотноси- 
мых индивидами с теми или иными социально одобряемыми ценностями, а значит, поиска методик сбора и анализа языковых данных, в том числе и экспериментальных, способных обнаружить автоматизированные речевые операции и эффективно исследовать структуру речевого действия. В этом смысле результативным может стать свободный ассоциативный эксперимент при условии интерпретации отношения «стимул - реакция», адекватной общей теории деятельности [Леонтьев, 2004] и теории речевой деятельности [Леонтьев, 1969].

Кроме того, как упоминалось ранее, экспериментальная проверка различных гипотез и выводов, касающихся проявлений асимметричности культур, осуществляется недостаточно, в том числе и при сопоставлении значений лексических единиц, поскольку оно чаще опирается на лексикографические источники, которые, что вполне естественно, не могут зафиксировать динамику единиц языка, связанную с «языковыми вмешательствами» [Гумбольдт, 1984, c. 318$]$ индивида в действительность. Между тем экспериментальное обнаружение психологически актуального содержания, стоящего за сопоставляемыми словами, может помочь решению этой задачи, важной как самой по себе, так и в связи с определением национальной специфики картин мира носителей разных лингвокультур, поскольку значение слова фиксирует «ставшее достоянием моего сознания... обобщенное отражение действительности, выработанное человечеством и зафиксированное в форме понятия, знания или даже умения как “обобщенного образа действия”, “нормы поведения” и т. п.» [Леонтьев, 2004, с. 242]. Свободный ассоциативный эксперимент, в котором носители языка реагируют на словостимул, не обдумывая его, обнаруживая актуальный для них смысл стимула в данных условиях ассоциирования, осуществляя в речевом действии акт предикации, предоставляет исследователю все перечисленные выше вербализованные формы существования опыта.

В психолингвистике теоретически обосновано и экспериментально верифицировано представление о том, что явления действи- тельности, воспринимаемые человеком в структуре его деятельности и общения, отображаются в сознании в виде причинных, временных, пространственных и других связей явлений и эмоций, фиксирующихся в ассоциативно-вербальной сети [Караулов, 1999]. Поэтому ассоциативное поле слова (далее - АП) специфически отражает стоящее за ним содержание: знания, вербализованные и невербальные, универсальные и национально специфичные, а также ментальные «правила» оперирования ими.

Характер актуальных реакций на словастимулы позволяет моделировать содержание сло́ва на материале, обладающем психической значимостью для индивидов, а не только на основе лексикографических источников, содержащих лексические инварианты.

При этом методологически важно представить объект, в котором совмещаются социальные, психологические и иные аспекты коммуникации. Таковым является речевое действие, специфика которого определяется в отношении «стимул - реакция». Это отношение устанавливается в свободном ассоциативном эксперименте, максимально приближенном к условиям стихийной речевой деятельности [Леонтьев, 1969].

В данной статье теоретически обосновывается методология анализа ассоциативного поля по совокупности признаков ассоциирования, которые позволяют эффективно сопоставлять фрагменты картин мира носителей разных языков. Интерпретация отношения «стимул - реакция», а не конкретного содержания ассоциата, позволяет предложить принципиально иные параметры моделирования АП в сопоставляемых языках, которое сейчас строится, как правило, только на частотности ассоциатов [Васильева, 2017]. Специфика характера предикации между стимулом и реакцией проявляется в признаке ассоциирования. По сути, определение такого параметра и есть установление специфики речевого действия. Признак ассоциирования, повторяющийся в разных зонах АП, позволяет обнаружить с достаточно высокой степенью точности мотив речевого действия и может стать основанием для установления семантической разницы сопоставляемых значений. 
В.А. Пищальникова. Эксперимент как составная часть методологии сопоставительных исследований

\section{Методология}

\section{экспериментального исследования}

Известно, что ядро АП вербального стимула фиксирует, как правило, стереотипное использование лексемы в типичных коммуникативных ситуациях (наиболее частотную их сочетаемость) [Караулов, 2000]. Ядра ассоциативных полей соотносимых слов разных языков могут внешне совпадать / не совпадать по количеству выделенных в них смысловых признаков, а также существенно различаться по их содержанию и иерархии компонентов. В ближней и дальней периферии АП концентрируются реакции, эксплицирующие личностные смыслы, которые отражают разную степень отхождения от типичного словоупотребления в связи с мотивом конкретного речевого акта, что дает достоверный материал и для анализа семантических изменений слова. Вместе с тем ассоциаты периферийных зон поля могут, хотя и в разной мере, представлять смысловые признаки ядра (подробно см.: [Пищальникова и др., 2019]). При этом именно эксперимент способен выявить характер и разную «скорость» динамики ассоциативных полей сопоставляемых слов.

\section{Гипотеза исследования}

Снижение числа актуализируемых признаков ассоциирования в разных (часто во всех) зонах АП определяет его специфику и характер динамики значения слова-стимула. Как правило, этот процесс сопровождается: снижением коэффициента разнообразия реакций и количества единичных реакций; количественным преобладанием понятийных и операциональных реакций над эмоционально-оценочными и реакциями-представлениями в результате ослабления индивидуальных ассоциативных связей со словом; уменьшением количества метафорических и национально специфичных или культурно значимых реакций на слово; изменением положительной коннотации лексемы на нейтральную или отрицательную; возрастанием числа отказов от ассоциирования, поскольку слово практически перестает использоваться в актуальной речевой деятельности и утрачивает ранее характерные для него ассоциативные связи.

\section{Анализ результатов эксперимента}

\section{Характеристика ассоциативного поля}

\section{«вежсливый»}

Аргументируем сформулированную гипотезу экспериментальным исследованием синонимического ряда с доминантой вежливый, некоторые компоненты которого, традиционно относимые лексикографической практикой к синонимам, психологически актуальной для носителей языка таковыми не являются [Пищальникова, Яо, 2019]. Ограниченные рамки статьи не позволяют представить анализ всех компонентов синонимического ряда, поэтому мы акцентируем самые показательные процессы в его динамике. При этом цель исследования - показать методику анализа АП, позволяющую устанавливать такие процессы и определять специфические параметры для его моделирования.

Наш эксперимент был направлен на решение нескольких задач: установить актуальное психологическое содержание, связываемое исследуемой группой носителей современного русского языка с лексемой вежливый; выявить возможную динамику ее содержания; показать наличие соответствий / несоответствий структуры ассоциативных полей соотносимых слов при изучении разных языков (русского и китайского).

В эксперименте принимала участие 1000 респондентов в возрасте от 17 до 25 лет (критерии их отбора составлены по Российскому ассоциативному словарю (РАС)). Экспериментальная анкета (в разных вариациях) включала 12 слов-стимулов: вежливый и его синонимы учтивый, корректный, предупредительный, обходительный, любезныцй, деликатный, услужливый, отзывчивый, тактичныци, куртуазный, галантный, отобранных на основе лексикографических данных и обратного эксперимента на слово вежливый. Из всего массива полученных анкет приемом случайных чисел для детального анализа было отобрано 120.

Условия проведения эксперимента стандартные: при предъявлении анкеты, в которой необходимые для анализа слова-стимулы перемежались словами-дистракторами, было предложено отреагировать «первым пришед- 
шим в голову словом», то есть не обдумывая стимул, в ограниченное экспериментатором время.

В состав АП лексемы вежливый вошли следующие реакции: человек 24, воспитанный 14, добрый 6, обходительный 4, учтивый 4, ответ 3, хороший 3, воспитание 2, галантный 2, интеллигент 2, приятный 2, ребенок 2, солдат 2, аргумент, благодарный, вежливые люди, вопрос, воспитанность, внимательный, галстук, гость, гражданин, грубый, джентльмен, добродушный, добр в общении, друг, здравствуйте, интеллигентный, лось, любезный, люди, милый, мужчина, начальник курса, незнакомый, общительный, опрятный, поступок, преподаватель, приветливый, приличный, пример, салфет-

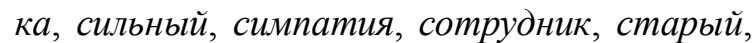
странный, сын, тактичность, толерантный, тон, улыбка, уступчивый, ученик, иве$m b l(120 / 57 / 6 / 44$ - общее количество реакций / количество разных реакций / количество отказов испытуемых от ассоциирования / количество единичных реакций).

В ядро поля условно включаем ассоциаты с частотностью не ниже 4: человек 24, воспитанный 14, добрый 6, обходительный 4, учтивый 4 , в ближнюю периферию-ответ 3 , хороший 3 , воспитание 2 , галантный 2 , интеллигент 2, приятный 2, ребенок 2, солдат 2, аргумент, все остальные реакции относятся к дальней периферии. Следует отметить, что существуют разные точки зрения на формирование зон АП. Так, многие исследователи не разграничивают ближнюю и дальнюю периферию поля, а выделяют ядро, куда включаются все неединичные реакции, и периферию, состоящую из единичных реакций (см., например: [Баландина, 2019]). Такая точка зрения логична, если ассоциаты интерпретируются вне предикативной связи со стимулом, а только на основе словарей. Однако если, вслед за А.А. Леонтьевым, рассматривать соотношение «стимул - реакция» как речевое действие, направленное на реализацию личностного смысла (а именно он интересует психолингвиста прежде всего) в ядро поля следует поместить именно единичные реакции, а частотные реакции, как правило перациональные, реализуют устойчивое психологическое значение, «замыкают» границы АП сло- ва. Обоснование такой модели - предмет особого разговора, и в рамках данной статьи мы лишь обозначим проблему, используя традиционный признак выделения ядра АП - частотность реакций, с тем чтобы акцентировать только доказательство заявленной гипотезы.

Наибольшее количество ассоциатов представлено операциональной (неосознаваемо воспроизводимой) реакцией человек, что позволяет выделить в ядре поля операциональный параметр (признак) 'носитель качества', отражающий стереотипное представление о человеке как носителе качества 'вежливый'.

Кроме того, в ядре ассоциативного поля актуализируются признаки 'соблюдение приличий', 'положительное отношение к личности другого человека'. Процентное соотношение ассоциатов, актуализирующих выделенные признаки, таково: 54,55 : 31,81 : 13,64. В центре ядра АП находится ассоциат, свидетельствующий о неосознаваемой актуализации лексемы, не представляющей личностного содержания, но актуализирующий стереотип. Коэффициент разнообразия реакций $-0,6$, что также свидетельствует о значительной степени стереотипности ассоциатов носителей русского языка.

Почти для трети респондентов вежливый и вежливость не обязательно связываются с этикетом: признак 'соблюдение приличий’ (этикет) реализуется у русских лишь в $31,81 \%$ реакций. Не отражена в ядре АП русских и иерархичность в реализации вежливого поведения.

Все отмеченные ядерные признаки представлены и ассоциатами ближней периферии обходительный 4, учтивый 4, ответ 3 , хороший 3 , воспитание 2 , галантный 2 , интеллигент 2, приятный 2, ребенок 2 , солдат 2. Признак 'соблюдение приличий' реализуется в $57,7 \%$ реакций, 'носитель качества' - в 23,1\%, 'положительное отношение к личности другого человека' - 19,2\%. Коэффициенты разнообразия ассоциатов в этой части $-0,38$.

В дальней периферии ядерные признаки АП также представлены: 'носитель качества' - вежливые люди, гость, гражданин, джентльмен, друг, люди, мужчина, начальник курса, незнакомый, преподаватель, сотрудник, старый, сын, ученик (выделены ре- 
акции, которые могут быть истолкованы неоднозначно); 'соблюдение приличий'- благодарный, внимательный, воспитанность, интеллигентный, любезный, приветливый, приличныц, тактичность, толерантный, yступчивый; 'положительное отношение к личности другого человека' - добродушный, добр в общении, симпатия.

Вместе с тем в дальней периферии состав признаков, отчасти повторяясь, закономерно расширяется: 'средство проявления приличия' - аргумент, вопрос, галстук, здравствуйте, опрятный, поступок, пример, салфетка, тон, улььбка, иветы; характер проявления вежливости'- общительный; 'антонимическое противопоставление слову-стимулу' - грубый; 'эмоциональное отношение к носителю признака, представленного словомстимулом'- странныци, лось, сильный. Такие признаки говорят о том, что для носителей русского языка важны внешние показатели вежливости, что косвенно свидетельствует о формальном характере базовой ценности «вежливость».

Основной признак ассоциирования, выделяемый в ядре АП стимула 礼貌的 / вежливый - 'носитель качества': 孩子 / ребенок 32, 学生 / учащийся (ученик и студент) 27, 我 / я 17 , 人 / человек 12, 同学 / одноклассник 9 ( 54,3\% реакций). При этом два ассоциата 礼节 / этикет, 问候 / приветствия - интерпретируют понятийное значение слова и представляют признак 'этикет', что связано с устойчивыми традициями реализации вежливости как ритуала. В ядерных ассоциатах представлен и признак 'иерархичность в реализации вежливого поведения': самым вежливым должен быть 孩子 / ребенок как младший по возрасту, далее - 学生 / учащийся (ученик и студент) как человек, всегда занимающий подчиненную ступень в социальной иерархии и 我 / я как индивидуальное приятие необходимости быть вежливым. 同学/ одноклассник, однокурсник демонстрирует актуальность категории лица в китайской культуре: равные по статусу люди, как и другие, должны быть вежливыми по отношению друг к другу. 人 / человек - операциональная реакция, указывающая на абстрактного носителя морально-этической категории. Выделенные признаки в полной мере соответствуют традиционным представлениям китайцев о вежливости как необходимой коммуникативной составляющей, реализующейся в определенных ритуалах.

В ближнюю периферию вошло 25 различных ассоциатов с разной частотностью (29,04\% от общего количества реакций). В этой группе выделяются следующие смысловые признаки, актуальные для респондентов: 'носитель качества' - 朋友/ друг, 女孩子 / девушка, 绅士 / чиновник в отставке или крупный землевладелец, имеющий хорошее образование, 我们/мы, 狗/ собака, 弟弟/ младший брат 2, 中国人 / китаец 2; 'форма реализации этикетного поведения’ - 握手 / пожать руку, 微笑 / улыбка, 你好 / привет. При этом признак 'иерархичность в реализации вежливого поведения' реализуется не так очевидно, как в ядре АП. Большинство ассоциатов ближней периферии актуализирует самый частотный признак ядерной зоны АП. В дальней периферии представлены следующие признаки ассоциирования: 'носитель качества' - 晚辈 / младшее поколение, 书生 / кабинетный ученый, 年轻人 / молодой человек, 青年 / молодежь, 长辈 / старшее поколение, 工人 / рабочий, 少年 / юноша, 陌生人 / незнакомец, 好孩子 / хороший ребенок (обычно речь идет о послушных детях), 好人 / хороший человек, 少先队员 / пионер, 少年/ юноша, 陌生人 / незнакомец; 'способ реализации этикета' - 榜样 / образец, 说话 / говорить, 发言 / выступить с речью, 文学/ литература; ‘формы реализации этикета' - 穿着/ наряд, 打招呼 / поздороваться, 送礼 / делать подарки, 谢谢 / спасибо; 'условия проявления вежливости” - 初次见面 / встретиться впервые, 音乐会 / торжественный вечер, концерт; 'исторические истоки вежливости' - 汉朝 / династия Хань. В этой зоне АП актуализируются выделенные ранее ядерные, а также дополнительные признаки. Таким образом, очевидно несовпадение состава признаков ассоциирования в русском и китайском ассоциативных полях.

Особенно важно подчеркнуть, что при сопоставлении ассоциативных полей носителей разных языков необходимо устанавливать не только сходство и различие в признаках ассоциирования, что уже само по себе показательно, но и в мотивах выбора того или иного признака. Например, ассоциация коррупщия - деньги характерна для русских и 
китайцев, но она представляет разный способ мотивации речевого действия, поскольку для китайца значимое условие коррупции - личные качества взяточника и взяткодателя, для русского - социальные условия, в которых взяткодатель «действует не по своей воле». Второй общий смысловой компонент, объединяющий часть понятийных ассоциатов АП коррупция, - коррумпированная среда: в русском - власть 18, государство 14, Россия 8, правительство 3, органы 3, страна 2, власть в РФ, Госдума, общество, система; в китайском - 政治/ политика 4, 权力/ власть 3, 体制 / система 2, 制度 / строй 2 [Пэй, 2018]. Однако этот признак тоже мотивирован поразному: носители русского языка считают, что коррумпирована прежде всего власть (государство) и ее институты; примечательно, что прямое указание на коррупцию во власти в китайских ассоциатах представлено не частотно - 权力 / власть 3, а на первое место выходит политическая коррупция. Если суммировать китайские ассоциаты, объединенные признаком 'коррумпированная среда', то их количество (11 из 200; ср. в русском - 52 из 200) указывает на принципиальное доверие к власти и перенесение ответственности за коррупцию на конкретных чиновников и граждан. Третий смысловой признак, объединяющий часть понятийных ассоциатов, - 'носители коррупции': в русском: чиновник 18 , полицейский 5, депутаты 4, чиновничество, бюрокpaтия, annapam, чиновники, которые допущены к должности и управлению. В китайском языке: 贪官 / продажный чиновник 19, 官员 / чиновник 13, 政府 / правительство 13, 高官 / высокопоставленный чиновник 4, 官场 / чиновничьи круги 2, 官僚体系 / бюрократическая система 2, 官僚 / бюрократия. Количество ассоциатов у носителей китайского языка больше, но только за счет детализации понятия «чиновник». Показательно, что китайцы не соотносят коррупцию с полицией и депутатами, реакция 廉政 / честное и неподкупное правительство указывает на положительное отношение к нему, закрепленное в актуальном лозунге, тогда как в русских ассоциатах проявляется однозначно негативное отношение к правительству. Коррупция рассматривается носителями обеих культур и как преступление: в русском языке-преступление 5 , взя- точничество, в китайском - 贪污 / казнокрадство 11, 犯罪 / преступление, 公款吃喝 / устроить банкет за счет государства. Только в китайских ассоциатах отмечены реакции, которые свидетельствуют о наличии четкой противопоставленности понятий «коррупция»«антикоррупция»: 反腐败 / антикоррупция 5, 廉洁 / неподкупность 5, 正义/ справедливость 3, 廉政 / честное и неподкупное правительство, 正直 / честный. В русском АП обнаруживается единичная операциональная реакция анти.

Анализ АП по признакам ассоциирования с целью верификации полученных результатов необходимо сопоставить с распределением компонентов АП по группам, отражающим характер знания, репрезентируемого словом, представляющим разную степень обобщенности основных компонентов значения: понятийные, эмоционально-оценочные, реакциипредставления, операциональные [Пищальникова, 2002]. Такое распределение позволяет понять, какие из них наиболее подвижны в семантическом плане и выявлять степень сформированности значений слов и понятий, выраженных лексемами, а также специфику закрепления слова в ассоциативно-вербальных сетях индивидов.

В АП «вежливый» выделим понятийные реакции: воспитанный 14, обходительный 4 , учтивый 4 , воспитание 2 , галантный 2 , благодарный, воспитанность, внимательный, интеллигентный, любезный, общительный, опрятный, приветливыци, приличный, тактичность, толерантный, уступчивый; реакции-представления: интеллигент 2 , ребенок 2, солдат 2, галстук, гость, гражданин, джентльмен, друг, мужчина, начальник курса, незнакомый, старый, сын, ученик, иветы, преподаватель, здравствуйте, сотрудник, пример, салфетка, лось; эмоциональнооценочные: добрый 6, хороший 3 , приятный 2 , мильий, странный, симпатия, сильный, добродушный, добр в общении; операциональные: человек 24, ответ 3, вежливые люди, аргумент, люди, улыбка, вопрос, тон, грубый, поступок.

Понятийные и операциональные реакции составляют $64,0 \%$ от общего количества ассоциатов: респонденты понимают значение слова и воспроизводят частотные сочетания с ним, но это только привычная форма реали- 
зации стереотипного отношения, тогда как психологически актуальные индивидуальные признаки в ассоциатах практически не отражены. Это подтверждается и составом реакций-представлений: они стереотипны, индивидуальные образы-представления не частотны - всего 0,6 \% (галстук, начальник курса, незнакомый, старый, лось). Эмоциональнооценочные реакции при этом ограничиваются выражением самых общих положительных характеристик (за исключением единичной реакции страннылй, наличие которой принципиально не меняет выявленных тенденций). Все сказанноепозволяет предполагать, что вежливость как морально-этическая ценность в исследуемой группе респондентов не актуальна.

С целью определения динамики АП сравним данные РАС и данные нашего ассоциативного эксперимента (по времени они отстают друг от друга от 12 до 33 лет; количество ассоциатов в полях сопоставимо: 102 и 120 при одинаковом количестве отказов): «вежливый: человек 29; отказ 6; мальчик 4; воспитанный, очень 3 ; интеллигент, мужчина, обходительный, ответ, приятно, учтивый, хороший 2; бегемот, бережливый, благовоспитанный, вежливость, великолепный, гад, господин, гость, гражданин, грубый, гусь, дедушка, джентльмен, дяденька, как ворона, клетка, кролик, культурный, лох, малый, парень, партнер, пацан, пес, подхалим, приятный, ребенок, слуга, старик, старичок, студент, такой, товарищ, уступчивый, учитель, хороший такой, черт, школьник, юноша, я 1; $102+55+0+43$ » (РАC, т. 1 , с. 80 ).

Очевидно совпадение значительной части операциональных ядерных ассоциатов сравниваемых полей, что свидетельствует о структурно-содержательной стабильности понятия, обозначенного словом вежливый, однако в РАС отмечены разговорные конструкции (вежливый очень, вежливый гад, вежливый такой), отсутствующие в экспериментальных данных 2018 года.

\section{Экспериментальное исследование слов синонимического ряда вежсливый}

Экспериментальное исследование синонимического ряда слова вежливыц свидетельствует о том, что ряд лексем, рассмат- риваемых лексикографическими источниками как синонимичные, не является таковым для респондентов изучаемой группы; часть слов этого ряда претерпевает значительные изменения, которые привели или могут привести к выпадению их из совокупности синонимов слова вежливый.

Для анализа мы отобрали слова-стимулы, входящие в АП «вежливый», как в разной степени синонимичные ему, так и получившие наибольшее количество отказов ассоциирования. Последнее свидетельствует о том, что слово редко включается в речевую деятельность, а, следовательно, понятие, обозначенное им, не является актуальным для носителя языка. Если количество отказов значимо, это может свидетельствовать о том, что выраженное словом-стимулом понятие находится в процессе изменения содержания и в силу этого изменяется его частотность.

\section{Характеристика ассоциативного поля «деликатный»}

В ядро АП входят реакции, которые представляют следующие признаки: 'качества, определяющие понятие' - тактичность 14, аккуратность 10, вежливость 10, обходительность 10, мягкость 7, осторожность 7, воспитанность 6, тонкость 5; 'средство проявления качества' - манеры 7 (210/78/33/52). Ядро АП определяется понятийными реакциями, составляющими 33,6 \%. В реакциях-представлениях отмечено 7 одинаковых ассоциатов, что свидетельствует о семантической освоенности слова, но одновременно и о стереотипности ассоциативных связей.

В ближней периферии, помимо указанного признака, реализуются 'условие развития и проявления деликатности' - ум 2, осторожность 2, уместность 2, уважение 2, воспитание 2, 'носитель качества' - мама 2; 'сфера проявления деликатности' - в общении 2, которые обнаруживаются и в дальней периферии, но в последней зоне АП актуализируются и другие: 'средство проявления качества' - перчатки, 'причина проявления качества' - вынужденный. При общей характеристике поля единичные реакции, как правило, не учитываются, но мы полагаем, что их анализ является необходимым для установ- 
ления специфики АП, поскольку такие ассоциаты указывают на потенциальное направление изменения значения слова-стимула.

Большое количество понятийных реакций свидетельствует о том, что личностного смысла у слова-стимула в процессе речевого действия практически не возникает: носители языка используют для предикации, как правило, интерсубъектные понятийные признаки. Отсюда можно заключить, что деликатность не является частотной единицей для представления психологически актуальных смыслов в речевой деятельности респондентов и не обозначает понятия, аксиологически значимого для них. Такой вывод подтверждается операциональными реакциями (стирка 3 , в общении 2, проблемы 2), количество которых возрастает в дальней периферии (общение, нужна, в вопросе, в разговоре, вопроса, проявлять, замечание, отночение, подход, ульб$\kappa a)$ и в целом составляет $0,9 \%$ от общего числа реакций.

Показательно, что в эксперименте обнаруживается незнание значения слова-стимула, приводящее к смысловой аттракции слов деликатесный и деликатный: деликатесный, меню, еда, пирожное, краб. Сделанные выводы подтверждаются низким процентом разнообразия реакций $(0,38 \%)$, большим количеством отказов от ассоциирования $(15,7 \%$ респондентов) и ассоциированием контрольной группы на стимул деликатный: человек 14 , вежливый 5, тактичный 5, вопрос, старик, воспитанный, ответ, еда, продукты.

\section{Характеристика ассоциативного поля «предупредительный»}

Еще более показательно АП стимула предупредительность в контрольной группе: осторожность 10, заранее 3 , страх 2 , разумный, качество, предосторожность, опасность, опасение, гордость, командир (30/10/8/7). Очевидно, что большая часть ассоциатов, входящих в него, обнаруживает непонимание значения слова-стимула и его деривационных связей: $66,7 \%$ реакций связываются со значением 'предупреждать' как «1. несов. перех. заранее ставить кого-л. в известность, уведомлять о чем-л.; 2. а) своевременно принятыми мерами опережать чьи-л. действия, предотв- ращать что-л.; б) предугадывая, исполнять (чье-л. желание, намерение и т. п.)» (СРСРЯ, т. 2, с. 278).

В понятийных реакциях поля «предупредительность» актуализируется семантический признак 'предостеречь, предостережение', так как респонденты не знают значения слова предупредительность и не включают его в синонимический ряд слова вежливый (осторожность 10, заранее 3 , разумный, предосторожность, качество, опасность, опасение, гордость). Непонимание значения слова, проявившееся во всех ассоциатах, в том числе частотных, свидетельствует о его неупотребительности в речевой деятельности респондентов (страх 2, командир). Важно и то, что в этом АП отсутствуют эмоционально-оценочные реакции, в которых наиболее ярко представлена субъективная мотивация индивида, и операциональные реакции, которые отражают, как правило, умение индивида использовать частотные словосочетания. Наконец, 8 отказов из 30 подтверждают, что респонденты не используют данный стимул в своей речевой деятельности. Следовательно, состав АП с очевидностью обнаруживает, что респонденты не соотносят стимулы предуnредительный / предупредительность с АП «вежливость», и это указывает на изменение состава синонимического ряда с доминантой вежливый. Контрольный эксперимент 2019 г. на слово-стимул предупредительный показал: в $100 \%$ реакций выявляется значение 'своевременно принятыми мерами опережать чьи-либо действия': выстрел 16, сигнал 9, paкета 2 , окрик 1.

\section{Характеристика ассоциативного поля «тактичный»}

Ассоциаты на стимул тактичный (190/ 75/4/33) мы рассматриваем в связи с большим количеством отказов на ассоциирование: $\sim 1,6 \%$.

Большая часть понятийных ассоциатов объединяется значением 'внешний признак поведения'; значительно количество операциональных реакций: 1,13\% (подход $4, \operatorname{xod~4,~}$ поступок 4, вопрос 3, тон, слово); всего $\sim 1,4 \%$ реакций поля актуализируют признак 'осторожный, бережный' (аккуратный 4, ос- 
B.А. Пищальникова. Эксперимент как составная часть методологии сопоставительных исследований

торожный 3, понимающий 2), нет ассоциатов, представляющих признак 'чувство меры', характеризующий специфику значения слова тактичный.

Часть ассоциатов актуализирует признаки лексемы тактический, что косвенно свидетельствует о ее непонимании: тактический 3 , правильный 2 , стратег 2 , стратегия 2 , танк 2, думаюший 2, план 2, умный 2, хитрость 2, бой, игрок, предусмотрительный, расчетливый, оперативный, межнациональный, логичныгй, хитрый, часы. О непонимании слова тактичный свидетельствуют также ассоциаты пунктуальный 4, точный 2 , дотошный, порядок, представляющие признак 'точный', фонетическое ассоциирование тактичный - практичный, неоднозначно интерпретируемые реакции боязнь, демократичныгй, скользкий, честность, недифференцированная положительная оценка: хороший, а также 17 отказов на ассоциирование.

\section{Характеристика ассоциативного поля «участливый»}

Актуальное разрушение состава синонимического ряда вежливый подтверждается и ассоциативным полем «участливый» (81/26/ 15/17). В ядре наибольшую частотность имеют ассоциаты активный 25, человек 12, активность 5, неравнодушный 5, показывающие, что $\sim 89,4 \%$ респондентов производят слово от участвовать в значении 'совместно действовать, быть сотрудником в чем-нибудь, действовать в каком-нибудь общем деле, принимать участие в чем-нибудь'. Это подтверждается: реакциями периферии поля (инициативный 4, конкурс 4, активист 3, инициатива 3, соревнование 3, актив, бегун, везде и всегда, время препровождать, интерес, интересный, искатель, квест, класс, торжественный вечер, концерт, завсегдатай, избиратель, работа в команде, уборка, учение, шустрый); самым высоким коэффициентом разнообразия ассоциатов, представляющих это значение, $-5,0$; большим количеством отказов от ассоциирования $1,8 \%$. Совокупность показателей говорит о том, что новое значение слова участливый, не отмеченное словарями, уже закреплено в ассоциативно-вербальных связях респонден- тов и активно функционирует в их речевой деятельности.

Вместе с тем в АП представлены и реакции, реализующие значение участливый как 'отзывчивый, готовый оказать помощь, содействие, обнаружить сочувствие, склонный к состраданию', но при всем разнообразии они не входят в ядро значения слова и частотность самой активной реакции более чем в 4 раза ниже частотности реакции, отражающей неверное толкование слова.

\section{Характеристика ассоциативного поля «услужливый»}

Еще более очевидно изменение в значении слова услужсливый (81/26/15/17). Респонденты дали $\sim 27,0 \%$ отказов на это словостимул, и АП «услужливый» (официант 12, слуга 12 , подлиза 12 , человек 12 , обходительныий 12 , помощь 9, прогнуться 6 , прислуга 3 , пассажир 2, низкий 2, вежливость 2, родители, умный, податливый, товарищ, юноша) имеет самый низкий уровень разнообразия $(0,03)$ среди всех полей стимула вежливый и его синонимов.

Доминантный смысловой признак, объединяющий 56,0 \% ассоциатов ядра поля, 'прислуживать'; в ядро поля входит также частотный признак 'негативное отношение к носителю качества' (подлиза 12): слово услужливый уже не воспринимается большинством респондентов как синоним к вежливый, чему способствует развитие отрицательной коннотации у слова, соотносимого респондентами с низкой социальной оценкой ряда профессий, представляющих обслуживающий персонал.

Отметим, что сходные тенденции изменения значения наблюдаются и в слове 殷勤的 / услужливый, особенно в группе эмоционально-оценочных ассоциатов, большее количество которых представляет негативную оценочность: 小人 / подлый человек 14. Данный ассоциат актуализирует признак 'низкий в нравственном отношении, бесчестный', 'выражающий низость, бесчестность', не отмеченный у лексемы 殷勤的 / услужливый ни в одном из китайских толковых словарей. Этот же компонент значения актуализирован частотными реакциями подхалимство, низко- 
поклонство, заискивать, держать камень за пазухой, злонамеренный, лицемерный, дурное дело, а также частотными ассоциатами плохой человек, прислужник, отвратительный, негодяй, предатель и др.

Представленный анализ ряда ассоциатов позволяет говорить не только о разрушении синонимического ряда вежливыци, но и косвенно свидетельствует о снижении актуальности вежливости как социально одобряемого отношения к окружающим в русской группе респондентов: она уже не является личностно актуальной, ценностной, а ограничивается самым общим представлением о ее содержании, внешних средствах и способах реализации.

\section{Выводы}

Анализ признака ассоциирования, лежащего в основе отношения между стимулом и реакцией, может использоваться как для эффективного выявления психологически актуальных смыслов, стоящих за словом в одном языке, так и для сопоставления значения слов (и выраженных ими понятий) и их динамики в разных языках. Предложенные нами параметры сопоставления ассоциативных полей универсальны и могут быть применены в сопоставительных исследованиях.

\section{СПИСОК ЛИТЕРАТУРЫ}

Баландина Е. С., 2019. Я-идентификация носителей русской, китайской и арабской культур // Филологические науки. Вопросы теории и практики. Т. 12, вып. 2. С. 95-98.

Васильева С. П., 2017. Динамика ценностных смыслов ассоциативного поля «Мир» в региональном языковом сознании сибиряков // Политическая лингвистика. № 2 (62). С. 19-26.

Гумбольдт В. фон, 1984. Избранные труды по языкознанию. М. : Прогресс. 397 с.

Караулов Ю. Н., 1999. Активная грамматика и ассоциативно-вербальная сеть. М. : Ин-т рус. яз. им. В.В. Виноградова РАН. 180 с.

Караулов Ю. Н., 2000. Показатели национального менталитета в ассоциативно-вербальной цепи // Языковое сознание и образ мира. М. : Ин-т языкознания РАН. С. 191-206.

Леонтьев А. А., 1969. Язык. Речь. Речевая деятельность. М. : Просвещение. 214 с.
Леонтьев А. Н., 2004. Деятельность. Сознание. Личность. М. : Смысл : Академия. 352 с.

Пищальникова В. А., 2002. Значение слова: к основаниям когнитивной семантики // Вестник Новосибирского государственного университета. Серия: История, филология. Т. 1, вып. 1. C. $73-83$.

Пищальникова В. А., Панарина Н. С., Степыкин Н. И., Хлопова А. И., Шевченко С. Н., 2019. Ассоциативный эксперимент: теоретические и прикладные перспективы психолингвистики. М. : Р-Валент. 200 с.

Пищальникова В. А., Яо Чжипэн, 2019. Служить бы рад - прислуживаться тошно, или Динамика значения слова 殷勤的/ услужливый в китайской лингвокультуре // Известия Юго-Западного государственного университета. Серия: Лингвистика и педагогика. Т. 9, № 1 (30). С. 56-65.

Пэй Цайся, 2018. Социально-философский аспект исследования антиценности «коррупция» (на материале русского и китайского языков) // Вестник Московского государственного лингвистического университета. Гуманитарные науки. Вып. 14 (809). С. 187-197.

\section{СЛОВАРИ}

$P A C-$ Русский ассоциативный словарь. В 2 т. Т. 1. От стимула к реакции / под ред. Ю. Н. Караулова. М. : АСТ : Астрель, 2002. 781 с.

СТСРЯ - Современный толковый словарь русского языка : в 3 т. Т. 2./ под ред. Т. Ф. Ефремовой. M. : ACT, 2006. $718 \mathrm{c}$.

\section{REFERENCES}

Balandina E.S., 2019. Ya-identifikatsiya nositeley russkoy, kitayskoy i arabskoy kultur [IIdentification of the Bearers of the Russian, Chinese and Arab Cultures]. Filologicheskiye nauki. Voprosy teorii i praktiki [Philological Sciences. Issues of Theory and Practice], vol. 12, iss. 2, pp. 95-98.

Vasilyeva S.P., 2017. Dinamika tsennostnykh smyslov assotsiativnogo polya «Mir» v regionalnom yazykovom soznanii sibiryakov [Dynamics of the Value Meanings of the Associative Field "Mir" in the Regional Linguistic Consciousness of Siberians]. Politicheskaya lingvistika [Political Linguistics Journal], no. 2 (62), pp. 19-26.

Humboldt V. fon, 1984. Izbrannye trudy po yazykoznaniyu [Selected Works on Linguistics]. Moscow, Progress Publ. 397 p. 
В.А. Пищальникова. Эксперимент как составная часть методологии сопоставительных исследований

Karaulov Yu.N., 1999. Aktivnaya grammatika $i$ associativno-verbalnaya set [Active Grammar and Associative-Verbal Network]. Moscow, Institut russkogo yazyka imeni V.V. Vinogradova RAN. 180 p.

Karaulov Yu.N., 2000. Pokazateli natsionalnogomentaliteta $\mathrm{v}$ assotsiativno-verbalnoy tsepi [Indicators of National Mentality in Associative-Verbal Chain]. Yazykovoe soznanie $i$ obraz mira [Linguistic Consciousness and Image of the World]. Moscow, Institut yazykoznaniya RAN, pp. 191-206.

Leontyev A.N., 2004. Deyatelnost. Soznanie. Lichnost [Activity. Consciousness. Personality]. Moscow, Smysl Publ., Akademiya Publ. 352 p.

Leontyev A.A., 1969. Yazyk. Rech. Rechevaya deyatelnost [Language. Speech. Speech Activity]. Moscow, Prosveshchenie Publ. 214 p.

Pishchalnikova V.A., 2002. Znachenie slova: k osnovaniyam kognitivnoy semantiki [The Meaning of the Word: To the Foundations of Cognitive Semantics]. Vestnik Novosibirskogo gosuniversiteta. Seriya: Istoriya, filologiya [Novosibirsk State University Bulletin. Series: History and Philology], vol. 1, iss. 1, pp. 73-83.

Pishhalnikova V.A., Panarina N.S., Stepykin N.I., Khlopova A.I., Shevchenko S.N., 2019. Assotsiativnyy eksperiment: teoreticheskie $i$ prikladnye perspektivy psikholingvistiki [Associative Experiment: Theoretical and Applied Prospects of Psycholinguistics]. Moscow, R-Valent Publ. 200 p.

Pishhalnikova V.A., Yao Chzhipen, 2019. Sluzhit by radprisluzhivatsya toshno, ili Dinamika znacheniya slova 殷勤的 / usluzhlivyy v kitayskoy lingvokulture $[<$ I will $>$ Serve, Willingly $-\mathrm{Be}$ Osequious, Never, or Dynamics of the Meaning of the Word 殷勤的 Pleasing in Chinese Language Culture]. Izvestiya Yugo-Zapadnogo gosudarstvennogo universiteta. Seriya: Lingvistika i pedagogika [Proceedings of the Southwest State University. Series: Linguistics and Pedagogics], vol. 9, no. 1 (30), pp. 56-65.

Pey Tsaysya, 2018. Sotsialno-filosofskiy aspekt issledovaniya antitsennosti «korruptsiya» (na materiale russkogo i kitayskogo yazykov) [SocioPhilosophical Research of the Anti-Value "Corruption" (A Contrastive Analysis of Russian and Chinese Languages)]. Vestnik Moskovskogo gosudarstvennogo lingvisticheskogo universiteta. Gumanitarnye nauki [Vestnik of Moscow State Linguistic University. Humanitarian Sciences], iss. 14 (809), pp. 187-197.

\section{DICTIONARIES}

Karaulov Yu.N., ed. Russkiy assotsiativnyy slovar. V 2 t. T. 1. Ot stimula k reaktsii [Russian Associative Dictionary. In 2 vols. Vol. 1. From Stimulus to Reaction]. Moscow, AST Publ., Astrel Publ., 2002. $781 \mathrm{p}$.

Efremova T.F., ed. Sovremennyy tolkovyy slovar russkogo yazyka. V 3 t. T. 2. [Modern Explanatory Dictionary of the Russian Language. In 3 vols. Vol. 2]. Moscow, AST Publ., $2006.718 \mathrm{p}$.

\section{Information about the Author}

Vera A. Pishchalnikova, Doctor of Sciences (Philology), Professor, Theory of Linguistics and Comparative Linguistics Department, Moscow State Linguistic University, Ostozhenka St., 38, 119034 Moscow, Russia, pishchalnikova@mail.ru,https://orcid.org/0000-0002-0992-0466

\section{Информация об авторе}

Вера Анатольевна Пищальникова, доктор филологических наук, профессор кафедры общего и сравнительного языкознания, Московский государственный лингвистический университет, ул. Остоженка, 38, 119034 г. Москва, Россия, pishchalnikova@mail.ru, https://orcid.org/0000-0002-0992-0466 